\title{
THE RESULTS OF MEDICAL AND SURGICAL TREATMENT OF ESSENTIAL HYPERTENSION
}

\author{
BY \\ MARJORY A. KEITH, * BARNET WOOLF, AND A. RAE GILCHRIST \\ From the Royal Infirmary, Edinburgh, and the Department of Public Health and Social Medicine, \\ Edinburgh University
}

Received March 8, 1949

For a variety of reasons it is difficult to evaluate the influence of therapeutic procedures in essential hypertension, the peculiar feature of which is an elevation of the diastolic blood pressure. Patients present individual problems and do not readily adapt themselves to precise categories and strict comparisons. Furthermore, while hypertension commonly runs a prolonged course over the years and shows of itself spontaneous fluctuations from day to day, yet for reasons unknown the intensity of the disease may abruptly increase and the pace towards a fatal termination quicken with unexpected suddenness. We have no measure of vascular vulnerability with which to compare one patient with another.

A feature of the disease, even in the same subject, is its variability. Symptoms pass through phases of activity and seldom correlate with the blood pressure readings. Arteriolar tone is not a fixed quantity. The diastolic pressure is constantly changing, occasionally falling to surprisingly low levels for no obvious reasons. It is remarkable how, after many months of intermittent disablement by headache or giddiness in middle life, a symptom-free stage may ultimately be attained in later years without, however, much significant alteration in the blood pressure. These natural variations and remissions hinder reliable therapeutic deductions in the individual patient. Nervous and emotional factors are difficult to assess and it is well recognized that the hypertensive patient is highly susceptible to suggestion-particularly when it is reinforced by the sympathetic care and understanding of an enthusiastic adviser. Psychological factors may distort the picture and obscure the basic facts.

By the study of a group of patients over a sufficiently long period the fallacies attributable to the inconsequential fluctuations of pressure and spontaneous remissions in symptoms are minimized to some extent. All our patients were under the care and supervision of the same observers: accustomed to the same surroundings, the same methods of clinical investigation and familiar with the ways of the examiners, they were thereby exposed to few extraneous factors liable to influence their nervous tension adversely. By the adoption of an attitude of benevolent neutrality, psychological influences were kept as uniform as possible from patient to patient. Each patient reported at intervals and was assessed by the same observers.

Many attempts have been made to judge the efficacy of the surgical attack on hypertension (Adson et al., 1934, 1936; Allen and Adson, 1940; Smithwick, 1940, 1944; and Grimson, 1947). Inadequate standards for comparison have proved a stumbling-block. Not infrequently an author has assembled two groups for comparison, one medically and the other surgically treated. To some extent the conclusions are invalidated by a comparison of the author's series of surgically treated patients with a medical group investigated by someone else necessarily employing slightly different standards, techniques, and methods. For example, Wagener and Keith (1939) report on a series of medically treated patients with hypertension and their results have been used by several surgical authors for comparison with their own cases; Flaxman (1944) describes a medical series of his own compared with the surgical experiences of Peet et al. (1940); Hammarström (1947) compares his surgical cases with a series of non-operated cases described by Bechgaard (1946), and so on. The general consensus of opinion is that sympathectomy is of value particularly in younger patients before the development of serious coronary or renal disease.

* Working under the tenure of a Scholarship awarded by the Grocers' Company of London. 
Hammarström (1949) believes that in the severer cases with retinal exudation life expectancy is increased in a sympathectomized group as compared with similar patients treated by medical means.

\section{The Problem}

The problem under consideration is the evaluation of the results obtained by medical and surgical means in the treatment of essential diastolic hypertension. This has involved a review of the progress of a large number of patients of whom some were surgically and some medically treated. The results are considered in general as well as in certain particular details. In the investigations now to be described, both " medical " and " surgical " groups have been examined and assessed by the same doctors, thus ensuring, it is hoped, more constant standards of comparison and hence more accurate conclusions. Surgery was first employed by us nine years ago. All the cases subsequently sympathectomized have been followed-up and form the basis of the present study. The control medical group dates back to five years ago.

\section{The Material}

The material on which our investigations are based consists of 151 cases of essential hypertension of whom 96 were treated by medical measures and 55 by surgery.

The investigations common to all the patients started on their admission to hospital. In general arteriosclerosis, angina, congestive heart failure, poor renal function, and an age in excess of 50 years, with few exceptions, were usually regarded as contraindications to surgical intervention, but minor cerebral episodes, even transient hemiplegias, did not exclude the possibility of surgical help. Changing standards of selection for surgery have proved of help to us in the construction of the two groups - surgical and medical-for the purposes of the present analysis of the results obtained.

When surgery was not employed the medical measures recommended were those in common use, including in the first instance a rest in bed in the hospital for two or three weeks, and thereafter some limitations in activities, a reduction in bodyweight when necessary, the administration of simple sedatives such as phenobarbitone and analgesics from time to time, the use of the " head-up " bed for the prevention of morning headache, and venesection very occasionally. Most emphasis was put on reduced activities and the avoidance of fatigue. In the surgical group Smithwick's (1940) method of lumbo-dorsal sympathectomy was employed in 75 per cent of the 55 patients and lumbar sympathectomy in the remainder treated several years earlier.
The medically treated group of 96 cases consisted of 76 benign (that is with retinal changes less than papillodema) and 20 malignant cases (that is with papillœdema accompanied or unaccompanied by other retinal changes); the surgically treated group of 55 was composed of 45 benign and 10 malignant cases.

The "benign medical" group consisted of 76 cases, 17 males and 59 females, varying in age from 30 to 71 , the average age being 47 years; the duration of the follow-up period varied from six months to five years. The "benign surgical " group was composed of 45 cases, 18 males and 27 females, varying in age from 19 to 60 , the average age being 40 years; the follow-up periods varied from three months to eight and a half years.

The " malignant medical" group contained 20 cases, 14 males and 6 females, varying in age from 31 to 66 , the average age being 50 years; the followup periods ranged from one month to one year. The "malignant surgical" group was composed of 10 cases, 5 males and 5 females, whose ages ranged from 36 to 61 , the average age being 46 years. Follow-up periods varied from three months to three years.

\section{METHOD OF INVESTIGATION}

Assessment of patients before and after treatment. The same routine of tests and investigations was applied to every patient in the series before treatment and at intervals after treatment. The methods employed consisted of a careful history to exclude any primary renal disease, endocrine disorder, or other cause for the hypertension. Particular attention was devoted to a routine physical examination with special note of the following points.

(1) Assessment of retinal grade according to the method of Wagener and Keith (1939) into four classes-1, 2, 3, and 4. (Normal is graded 0, papillœdema is graded 4 .)

(2) Assessment of cardiac efficiency, graded according to the following method: A, normal; B, slight impairment during exertion; C, considerable impairment during exertion; and $\mathrm{D}$, impairment at rest.

(3) Assessment of renal efficiency, according to results of the urea concentration range (Cameron, 1934) or the urea clearance tests (Peters and Van Slyke, 1946) thus: A, very good; B, good; C, fair; and $\mathrm{D}$, poor.

(4) Assessment of severity of symptoms, thus: A, symptom-free; B, moderate symptoms but fit for work; C, severe symptoms, unfit for work; and $D$, dead.

(5) Assessment of the diastolic pressure. As a measure of the peripheral resistance the diastolic 
pressure is recognized as a more reliable indication of the severity of the hypertensive process than the systolic level. Furthermore, the diastolic pressure has a smaller range of fluctuation than the systolic and is less susceptible to unpredictable excursions. For comparative purposes the diastolic pressure therefore yields the more reliable figure and we have made use of it in our assessment. The basic figures were taken when the patient, already thoroughly familiar with the method, had rested for at least 10 to 15 minutes recumbent on a couch. It must be realized that this reading was not taken until the end of the examination, by which time it was ensured that the patient was adjusted to his surroundings and completely at ease in a quiet restful room with which he was familiar. The diastolic pressure. is recorded in $\mathrm{mm}$. of mercury for each patient and not graded A, B, C, or D as for the other observations listed above.

During the clinical examination note was made of the physique and nutrition of the patient, the pattern of the electrocardiogram, and the heart-size - measured radiologically by the method of Ungerleider and Gubner (1942). These latter observations, however, had not all been made in every case before treatment, and therefore were discarded in the-statistical analysis of the results.

The construction of matched groups for comparison of results. The second part of the investigation consisted in dividing the patients into matched groups for the purpose of comparing the results of the two methods of treatment. As the hypertensive process as a rule runs a milder course in the female (Bechgaard, 1946; Rogers and Palmer, 1946-7) the surgical cases were divided on a sex basis. Each of these male and female groups was subdivided into smaller groups composed as far as possible of persons of similar ages and with similar grading in the tests listed above. This procedure resulted in the "surgical" cases being divided into 11 female and 8 male groups, as shown in Table I.

Next, each "medical" patient's results were carefully scrutinized, and he was placed in a " medical " group corresponding to the " surgical" group whose criteria he best fitted. Those medical cases who fitted exactly were termed " first-class comparisons "; those who fitted well, but deviated in one degree in any criterion other than retinal grade were termed "second-class comparisons"; those who fitted less well, but better into that group than into any other were called "third-class comparisons" and were excluded from the statistical assessment of results.

There now existed 8 male and 11 female groups each consisting of the original surgical cases and those medical cases that matched them, the matching
TABLE I

Composition of Groups of Surgically Treated PATIENTS

\begin{tabular}{|c|c|c|c|}
\hline Group & $\begin{array}{c}\text { Retinal } \\
\text { grade }\end{array}$ & $\begin{array}{c}\text { Cardiac } \\
\text { efficiency } \\
\text { grade }\end{array}$ & $\begin{array}{c}\text { Renal } \\
\text { efficiency } \\
\text { grade }\end{array}$ \\
\hline 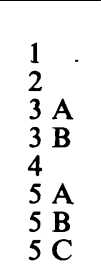 & $\begin{array}{l}0 \\
\text { I } \\
\text { II } \\
\text { II } \\
\text { III } \\
\text { IV } \\
\text { IV } \\
\text { IV }\end{array}$ & $\begin{array}{c}\text { Ales } \\
\mathrm{A} \\
\mathrm{A} \\
\mathrm{A} \\
\mathrm{B} \\
\mathrm{C} \\
\mathrm{A} \\
\mathrm{C} \\
\mathrm{D}\end{array}$ & $\begin{array}{l}\text { A } \\
\text { A } \\
\text { A-B } \\
\text { A-B } \\
\text { G } \\
\text { B } \\
\text { C } \\
\text { D }\end{array}$ \\
\hline $\begin{array}{ll}1 & \mathrm{~A} \\
1 & \mathrm{~B} \\
1 & \mathrm{C} \\
2 & \mathrm{~A} \\
2 & \mathrm{~B} \\
2 & \mathrm{C} \\
3 & \mathrm{~A} \\
3 & \mathrm{~B} \\
4 & \\
5 & \mathrm{~A} \\
5 & \mathrm{~B}\end{array}$ & $\begin{array}{l}0 \\
0 \\
0 \\
\text { I } \\
\text { I } \\
\text { I } \\
\text { II } \\
\text { II } \\
\text { III } \\
\text { IV } \\
\text { IV }\end{array}$ & $\begin{array}{l}\text { ales } \\
\text { A } \\
\text { A } \\
\text { B } \\
\text { A } \\
\text { A } \\
\text { C } \\
\text { A } \\
\text { C } \\
\text { A-B } \\
\text { B } \\
\text { C }\end{array}$ & $\begin{array}{l}\text { A } \\
\text { B } \\
\text { A } \\
\text { A } \\
\text { B } \\
\text { C } \\
\text { A } \\
\text { A } \\
\text { C } \\
\text { B } \\
\text { C }\end{array}$ \\
\hline
\end{tabular}

being done on the basis of their pre-treatment investigations. The addition of the medical cases as an " extension" to each surgical group caused no alteration in the description of any group as given in the above tables, since the third-class comparisons (which might have disturbed the homogeneity of a group) had been discarded. The final constitution of each " surgical-plus-medical " group which are the units on which the actual work of comparison and statistical analysis was done is presented in Table II. Amongst the males groups 1 to 4 , inclusive and amongst the females groups $1 \mathrm{~A}$ to 4 , represent cases of benign hypertension. Malignant hypertension is composed of groups $5 \mathrm{~B}$. and 5C male, and groups 5A and 5B female.

Of the total of 23 male surgical cases, 18 were benign and 5 malignant; and of the total of 27 medical cases used for the analysis (1st +2 nd class) 13 were benign and 14-malignant. Of the total of 32 female surgical cases, 27 were benign and 5 malignant; of the total of 47 female medical cases (1st class +2 nd class comparisons) 42 were benign and 5 were malignant (Table II).

The third class comparisons numbered in all 22 , 4 males and 18 females. Of the 4 males, all were benign cases; of the 18 females, 17 were benign, and 1 malignant.

It is customary to consider the adverse influence of obesity on the course of hypertension. It has 
TABLE II

Composition OF THE MATCHED GROUPS ON WHICH the Statistical Analysis is Based. The Third Class Comparisons are DisCaRded.

\begin{tabular}{|c|c|c|c|c|}
\hline \multirow[t]{2}{*}{ Group } & \multirow{2}{*}{$\begin{array}{l}\text { No. of } \\
\text { surgical } \\
\text { cases }\end{array}$} & \multicolumn{3}{|c|}{$\begin{array}{l}\text { No. of medical cases for } \\
\text { comparison }\end{array}$} \\
\hline & & 1st class & 2nd class & 3rd class \\
\hline $\begin{array}{l}1 \\
2 \\
3 \mathrm{~A} \\
3 \mathrm{~B} \\
4 \\
5 \mathrm{~A} \\
5 \mathrm{~B} \\
5 \mathrm{C}\end{array}$ & $\begin{array}{l}3 \\
5 \\
6 \\
2 \\
2 \\
3 \\
1 \\
1\end{array}$ & $\begin{array}{c}\text { Males } \\
3 \\
1 \\
1 \\
2 \\
2 \\
4 \\
2 \\
1\end{array}$ & $\begin{array}{c}\overline{2} \\
1 \\
1 \\
\overline{3} \\
\overline{4}\end{array}$ & $\begin{array}{l}- \\
\overline{-} \\
\overline{3} \\
1 \\
- \\
-\end{array}$ \\
\hline Total & 23 & 16 & 11 & 4 \\
\hline $\begin{array}{l}1 \mathrm{~A} \\
1 \mathrm{~B} \\
1 \mathrm{C} \\
2 \mathrm{~A} \\
2 \mathrm{~B} \\
2 \mathrm{C} \\
3 \mathrm{~A} \\
3 \mathrm{~B} \\
4 \\
5 \mathrm{~A} \\
5 \mathrm{~B}\end{array}$ & $\begin{array}{l}3 \\
1 \\
3 \\
2 \\
4 \\
7 \\
3 \\
3 \\
1 \\
4 \\
1\end{array}$ & $\begin{array}{c}\text { Females } \\
4 \\
3 \\
1 \\
2 \\
2 \\
3 \\
3 \\
3 \\
2 \\
3 \\
2\end{array}$ & $\begin{array}{l}\overline{3} \\
4 \\
2 \\
2 \\
2 \\
4 \\
2 \\
-\end{array}$ & $\begin{array}{l}-4 \\
2 \\
-\overline{2} \\
\frac{2}{6} \\
\frac{3}{1}\end{array}$ \\
\hline Total & 32 & 28 & 19 & 18 \\
\hline
\end{tabular}

been noted by many writers (e.g. Hunter and Rogers, 1923) that since an excess of body weight has an adverse bearing on the subject's expectation of life, it ought to operate even more severely to shorten the life span of the patient with hypertension. Bechgaard (1946), however, notes that contrary to expectation in his series of 1000 hypertensives which contained 311 obese patients, the latter had if anything a lower mortality than the others.

In our small series there were 7 cases of obesity amongst the male surgical patients ( 5 benign and 2 malignant) and 4 amongst the male medically treated cases ( 3 benign and 1 malignant). In the females, of those surgically treated, 6 benign and 2 malignant were obese, whilst of the medical series, 19 were markedly overweight. Obesity however had no relation to the mortality rate. Of the 7 " medical" deaths in the benign group only one was an obese individual; the remainder were under average weight. Of the 5 patients who died in the surgically treated group, 3 were under-weight and one average. Obesity did not correlate with any significant deterioration in the course of the followup. In fact in the most severe (malignant) hyper- tensive cases, loss of weight was noted in 65 per cent of the medical and 30 per cent of the surgical cases, and in the medical group it was an accompaniment of their rapid deterioration. Body weight is therefore disregarded in our groupings.

The adoption of matched groups is one which should meet Smithwick's (1948) requirements when he states: "Further comparison of surgically and non-surgically treated cases divided into similar sub-groups in which the most important variables are held constant is desirable. Until this can be done the influence and relative merits of various therapeutic measures upon the course of hypertensive vascular disease cannot be evaluated with certainty." Although the numbers in this investigation are small, our statistical colleague (B.W.) is satisfied that they are sufficiently large to provide information that is significant.

\section{Statistical Analysis}

It must be emphasized strongly that the reliability of this analysis depends entirely on the validity of the grouping and matching of the cases described above. In a clinical trial it is necessary that the allocation of cases to experimental and control groups shall be free from bias in respect of severity of symptoms, age, sex, or any other circumstance likely to have a bearing on prognosis. This is usually contrived by a deliberately planned experiment in which the cases are allotted to one or other form of treatment by a designed process. In the present investigation, however, this was not done; each patient was given surgical or medical treatment as seemed appropriate without strict regard to the possible future use of the cases in a statistical comparison.

It has been possible, however, owing to such factors as changing standards as to indications for operation, patients declining operation, and so on, to match our surgical groups with medical, on the basis of the observations made during the patient's first stay in hospital and thus the series of cases has been converted retrospectively into a properly controlled experiment to the best of our ability. All the patients had been under detailed observation in the wards of the hospital and had submitted to the same routine.

In the statistical analysis each group was taken separately and the "surgical " cases compared with the 1st and 2nd class "medical" cases therein. Six criteria are available for statistical evaluation; these can be divided into two sections. In the first the observations made at periodic re-examinations of those patients who survived are considered, particularly in regard to the following factors: (1) retinal grade, (2) cardiac efficiency, (3) renal 
efficiency, (4) symptom grade, and (5) diastolic blood pressure. The second part is a consideration of the incidence of deaths in relation to sex, severity of symptoms and method of treatment.

\section{Comparison by Symptoms and Signs}

In the analysis under this heading, the change was noted, for each patient, between the initial value or grade and that found at a specified time after treatment, in each of the items noted above. The choice of the time interval is of some importance. It is desirable to use as long a period as possible, to give ample time for the results of treatment to become manifest; a long interval also helps to reduce bias, by eliminating from the analysis all patients who die soon after the initial examination, and who therefore may have been too advanced in the disease to benefit from treatment. It also serves to minimize any effects attributable to psychological betterment and unintentional suggestion. On the other hand, increasing the time interval involves omission from the comparison of all the more recent cases. The best compromise is to base the main comparison on the difference between the initial findings and those at the examination most nearly coinciding with the first anniversary of the commencement of treatment, or of sympathectomy.

Data on change of symptom-grade are available for 47 surgical cases ( 20 male and 27 female) and 42 medical cases (11 male and 31 female), a total of 89 patients. Observations on criteria $1,2,3$, and 5 (see p. 288) are also on record for most of these cases. Comparisons of changes after three years were also made, but the number of cases was only 41; the findings for the one-year and three-year periods are fully concordant.

Criteria 2, 3, and 4 are on the $\mathrm{ABC}$ scale, an arbitrary value of unity being given to each successive step. Retinal grade is $0,1,2,3$, and 4 , as described earlier; blood pressure differences were measured quantitatively in $\mathrm{mm}$. Hg. In each group of patients the average change in the medically and surgically treated cases was calculated with respect to each criterion, and the probability that the observed difference, if any, might be attributable to chance fluctuations. The combined probability that all the differences with respect to treatment might be chance effects were then calculated. Where this probability is less than $1: 20$ the treatments are taken as giving significantly different results.

Results of anglysis. The main findings are as follows.

(1) In the symptom grading, the surgical cases show a great and decisive superiority over the medical. The details for a 12-months interval are shown in Table III. A positive value in the last

TABLE III

Mean Changes in Symptom Grade after One Year

\begin{tabular}{|c|c|c|c|c|c|}
\hline \multirow{2}{*}{ Group } & \multicolumn{2}{|c|}{ Surgical cases } & \multicolumn{2}{|c|}{ Medical cases } & \multirow{2}{*}{$\begin{array}{c}\text { Difference between } \\
\text { means* }\end{array}$} \\
\hline & No. & Mean improvement & No. & Mean improvement & \\
\hline $\begin{array}{l}1 \\
2 \\
3 \mathrm{~A} \\
3 \mathrm{~B} \\
4 \\
5 \mathrm{~A} \\
5 \mathrm{~B}\end{array}$ & $\begin{array}{l}3 \\
4 \\
5 \\
2 \\
2 \\
3 \\
1\end{array}$ & $\begin{array}{l}0.67 \text { grade } \\
2.00 \\
1.80 \\
2.00 \\
1.50 \\
1.33 \\
2.00\end{array}$ & $\begin{array}{c}\text { Male } \\
0 \\
2 \\
2 \\
3 \\
1 \\
0 \\
1\end{array}$ & $\begin{array}{r}\overline{0.50} \\
0.50 \\
0.67 \\
1.00 \\
-1.00\end{array}$ & $\begin{array}{l}\overline{1 \cdot 50} \\
1 \cdot 30 \\
1 \cdot 33 \\
0.50 \\
\overline{3.00}\end{array}$ \\
\hline $\begin{array}{ll}1 & \mathrm{~A} \\
1 & \mathrm{~B} \\
1 & \mathrm{C} \\
2 & \mathrm{~A} \\
2 & \mathrm{~B} \\
2 & \mathrm{C} \\
3 & \mathrm{~A} \\
3 & \mathrm{~B} \\
4 & \\
5 & \mathrm{~A} \\
5 & \mathrm{~B}\end{array}$ & $\begin{array}{l}3 \\
1 \\
3 \\
1 \\
3 \\
5 \\
3 \\
2 \\
1 \\
4 \\
1\end{array}$ & $\begin{array}{l}1.33 \\
1.00 \\
2.00 \\
2.00 \\
1.00 \\
1.20 \\
0.67 \\
2.00 \\
0.00 \\
1.50 \\
1.00\end{array}$ & $\begin{array}{c}\text { Femal } \\
4 \\
3 \\
3 \\
1 \\
4 \\
2 \\
5 \\
6 \\
2 \\
1 \\
0\end{array}$ & $\begin{array}{l}0.50 \\
0.33 \\
0.00 \\
1.00 \\
0.25 \\
0.50 \\
0.20 \\
0.33 \\
1.00 \\
0.00 \\
-\end{array}$ & $\begin{array}{r}0.83 \\
0.67 \\
2.00 \\
1.00 \\
0.75 \\
0.70 \\
0.47 \\
1.67 \\
-1.00 \\
1.50 \\
---\end{array}$ \\
\hline Total .. & 47 & $1 \cdot 43$ & 42 & $0 \cdot 38$ & 1.05 \\
\hline
\end{tabular}

* A positive value in the last column indicates that the surgical response was more favourable than the medical. The relief of symptoms one year after treatment in the surgical group is on the average superior to the medical. 
column means that the surgical cases did better. It will be seen that only in one group (female group 4, with one surgical and two medical cases) is there a minus sign. As might be expected, the combined test of significance shows an infinitesimal probability (less than $1: 1,000,000,000)$ that the superiority of the surgical cases is due to sampling fluctuation.

On the average, the surgical cases improved by about 1.4 symptom grades in the course of a year; almost all were able to work, and many were free from symptoms. In the medical cases, the average improvement was less than 0.4 of a symptom grade.

(2) In diastolic blood pressure, the medical cases show an average rise while the surgical cases show an average fall, and the difference is highly significant statistically. The amount of rise or fall did not seem to vary with the severity of the cases. It was therefore legitimate to pool all the surgical and all the medical cases. The means and some tests of significance are shown in Table IV. Although

\section{TABLE IV}

Mean Changes in Diastolic Blood Pressure AFTER ONE YEAR

\begin{tabular}{|c|c|c|c|}
\hline Cases & & No. & Mean change (mm. Hg.) \\
\hline $\begin{array}{l}\text { Surgical cases } \\
\text { Medical cases } \\
\text { Difference } \\
\begin{array}{ll}\text { t } \quad . \\
\text { p } \quad \ldots\end{array}\end{array}$ & $\begin{array}{l}\cdots \\
\cdots \\
\cdots \\
\cdots\end{array}$ & $\begin{array}{l}31 \\
30\end{array}$ & $\begin{array}{l}-8 \cdot 39 \\
+8 \cdot 37 \\
16 \cdot 76 \pm 5.08 \\
3 \cdot 30 \\
0.001 \text { approx. }\end{array}$ \\
\hline
\end{tabular}

the changes are statistically established, they are not very striking in magnitude, averaging $+8.4 \mathrm{~mm}$. $\mathrm{Hg}$. in the medical cases and $-8.4 \mathrm{~mm}$. $\mathrm{Hg}$. in the surgical.

(3) In the retinal grading there was a difference in favour of the surgical cases, which is just statistically significant. On the average the surgical cases improved in twelve months by 0.5 of a grade, while the medical cases showed no change.

(4) \& (5) Cardiac and renal gradings showed a difference in favour of surgical treatment which, however, in neither case was statistically significant.

The general conclusion from this part of the analysis is that among patients who survive a year or more, those who received surgical treatment are functionally and subjectively considerably better than those treated medically. The surgical cases also appear to be better on objective signs, blood pressure, and cardiac, retinal, and renal gradings. But the difference in the well-being of the patients is much greater than would be expected from these objective assessments.

\section{COMPARISON BY MORTALITY}

We now come to the consideration of the second part of the statistical analysis - the analysis of death incidence. Including all surgical cases and the first and second class medical comparisons, we have records of 128 patients, of whom 36 died. It was soon obvious that the death rate in the benign cases (groups 1 to 4 inclusive) was so widely different from that in the malignant cases (groups 5A, 5B, and 5C) that those two classes were best treated separately.

In the benign groups there are 45 surgical cases, with 5 deaths, compared with 55 medical cases, with 7 deaths. On the crude figures there is no evidence of any difference. This is confirmed by more refined analysis. These patients were of disparate ages, and had been under observation for periods varying from a few months to several years. The older the patient, and the longer the period under observation, the greater the risk of death. For each patient was calculated the chance of dying during the period of observation if he or she had the same death risk as prevailed for persons of like age and sex in the general population, as listed in the Life Table for Scotland for 1931. The period of risk for survivors was taken as the time since the first examination, and for deceased patients as the period from the first examination until death. The sum of the figures for all the patients in a group gives the number of " expected deaths." The data are shown in Table V.

It will be seen that there were 5 deaths in surgical cases, against the expectation of about $1 \cdot 1$; and 7 in medical cases against the expectation of about 1.3 deaths. This indicates that the death rates for persons with benign essential hypertension seeking hospital advice is about 5 times that prevailing in the population as a whole, and there is no evidence, on these small numbers, of any difference between medical and surgical cases.

\section{The Mortality Rate in Malignant HYPERTENSION}

Of the original medical group of 20 malignant hypertensive patients, 2 were unsuitable for inclusion in the statistical analysis, one being a thirdclass comparison already discarded, and the other dying a few days after admission to hospital. There remains for consideration the 10 surgical patients of whom 5 died, and 18 medical patients of whom 17 died. At first sight this suggests a strong recommendation of surgical treatment, but further detail is necessary to ensure that the groups are comparable. All the cases surgically treated-were regarded as suitable for operation by both physicians and surgeons with the exception of one patient, a woman who had been in congestive heart failure prior to 
TABLE V

Deaths in Patients with Benign Hypertension*

\begin{tabular}{|c|c|c|c|c|c|c|}
\hline \multirow{3}{*}{ Group } & \multicolumn{3}{|c|}{ Surgical cases } & \multicolumn{3}{|c|}{ Medical cases } \\
\hline & \multirow{2}{*}{$\begin{array}{l}\text { No. of } \\
\text { patients }\end{array}$} & \multicolumn{2}{|c|}{ Deaths } & \multirow{2}{*}{$\begin{array}{l}\text { No. of } \\
\text { patients }\end{array}$} & \multicolumn{2}{|c|}{ 'Deaths } \\
\hline & & Expected & Observed & & Expected & Observed \\
\hline $\begin{array}{l}1 \\
2 \\
3 \text { A } \\
3 \text { B } \\
4\end{array}$ & $\begin{array}{l}3 \\
5 \\
6 \\
2 \\
2\end{array}$ & $\begin{array}{l}\mathbf{0 . 0 7} \\
\mathbf{0 . 2 9} \\
\mathbf{0} \cdot 19 \\
\mathbf{0 . 0 2} \\
\mathbf{0 . 0 4}\end{array}$ & $\begin{array}{l}\text { Males } \\
1 \\
0 \\
0 \\
0 \\
0\end{array}$ & $\begin{array}{l}3 \\
3 \\
2 \\
3 \\
2\end{array}$ & $\begin{array}{l}0.06 \\
0.08 \\
0.04 \\
0.09 \\
0.03\end{array}$ & $\begin{array}{l}0 \\
2 \\
0 \\
0 \\
1\end{array}$ \\
\hline All male & 18 & 0.61 & & 13 & 0.31 & 3 \\
\hline $\begin{array}{l}1 \text { A } \\
1 \text { B } \\
1 \text { C } \\
2 \text { A } \\
2 \text { B } \\
2 \text { C } \\
3 \text { A } \\
3 \text { B } \\
4\end{array}$ & $\begin{array}{l}3 \\
1 \\
3 \\
2 \\
4 \\
7 \\
3 \\
3 \\
1\end{array}$ & $\begin{array}{l}0.04 \\
0.01 \\
0.09 \\
0.02 \\
0.08 \\
0.16 \\
0.06 \\
0.05 \\
0.02\end{array}$ & $\begin{array}{l}0 \\
0 \\
0 \\
0 \\
1 \\
2 \\
1 \\
0 \\
0\end{array}$ & $\begin{array}{l}4 \\
6 \\
5 \\
2 \\
2 \\
4 \\
5 \\
5 \\
7 \\
4\end{array}$ & $\begin{array}{l}0.07 \\
0.23 \\
0.16 \\
0.05 \\
0.07 \\
0.12 \\
0.08 \\
0.23 \\
0.04\end{array}$ & $\begin{array}{l}0 \\
0 \\
1 \\
0 \\
0 \\
0 \\
1 \\
0 \\
2\end{array}$ \\
\hline $\begin{array}{c}\text { All female } \\
\text { Total ... }\end{array}$ & $\begin{array}{l}27 \\
45\end{array}$ & $\begin{array}{l}0.51 \\
1.12\end{array}$ & $\begin{array}{l}4 \\
5\end{array}$ & $\begin{array}{l}42 \\
55\end{array}$ & $\begin{array}{l}1.02 \\
1.33\end{array}$ & $\begin{array}{l}4 \\
7\end{array}$ \\
\hline
\end{tabular}

* By comparing the expected deaths with the observed, the death rate in benign hypertension is approximately five times that prevailing in the population as a whole. There is no significant difference between our two groups of medically and surgically treated patients.

admission to hospital. In this case the surgeons were reluctant but were finally persuaded to intervene.

The medically treated cases were graded in three categories: (A) where there was no contraindication to surgical treatment; (B) where the physicians thought operation justifiable although one criterion fell short of the desirable level; and (C) cases where neither physicians . nor surgeons would advise operation, that is with severe renal or cardiac failure or both combined.

The surgical cases described above fell into category (A) with the exception of the one stated, who was graded (B). Details of the cases in these surgical and medical categories are given in Table VI.

It will be seen that of the 9 surgical (A) cases, 5 died after an average period of 13 months and 4 have lived for an average of 26 months after being first treated. There are 5 medical (A) cases all of whom died after an average interval of 5 months. The only surgical (B) case has not died after an interval of 14 months; out of 9 medical (B) cases, 8 died after an average of 1.8 months, and one has survived for the short period of 3.5 months. The 4 medical (C) cases died after an average interval of $1 \cdot 3$ months.
The only valid control for the main body of surgical malignant cases is the (A) group of medical patients. As far as they go the comparative death rates in (A) and (B) categories appear to favour surgical treatment. The data however are insufficient for a definite decision. The physicians in charge of the medical (A) cases are of the opinion, on clinical grounds, that these patients would have lived longer had they been treated surgically; but for statistical purposes a much larger series of malignant cases is required. It seems unlikely that this will be obtained in cases fit enough for operation, because this will not be refused in future merely in order to provide a control group. But there is a prospect of an entirely ethical future experiment. In the (B) cases, where the physicians believe operation would be beneficial and the surgeons regard it as too hazardous, the opinion of the surgeons has hitherto usually prevailed. If it could be agreed that in future half these cases, chosen by a random process, could be operated on, and the other half kept as controls, decisive information about the value of operation in the most severe cases might be forthcoming. Since in the absence of surgical treatment these patients have an 
TABLE VI

Deaths in Patients with Malignant Hypertension

(A) No contraindication to surgical treatment

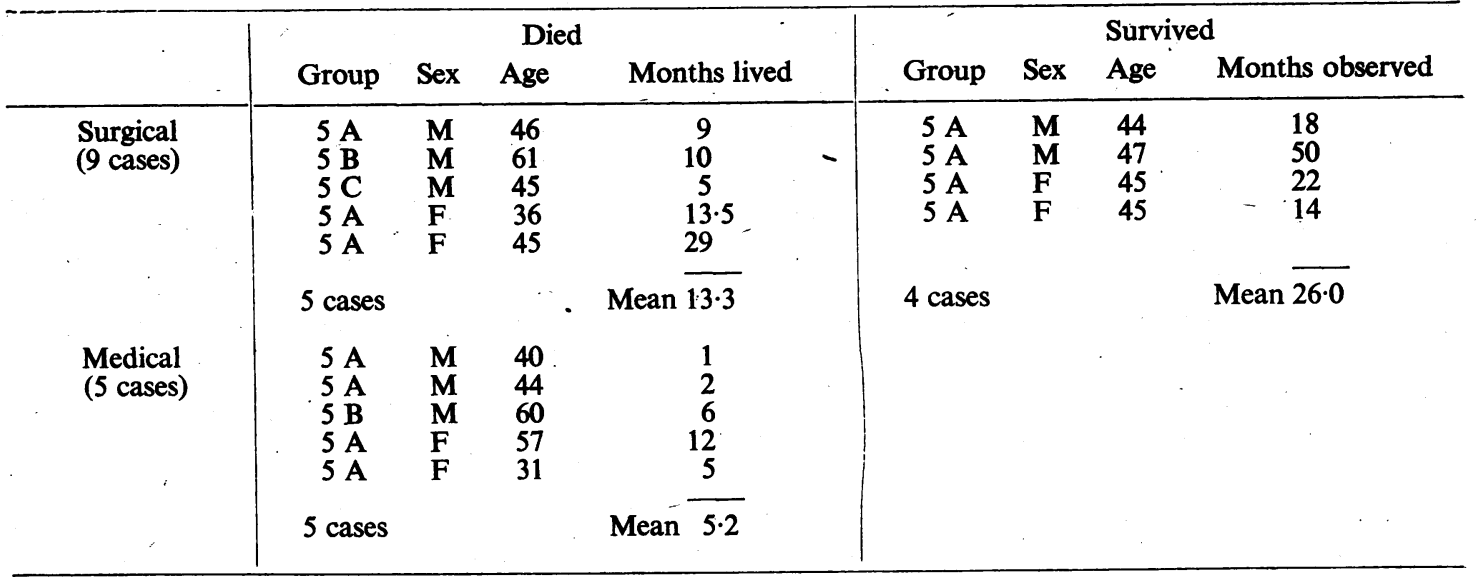

(B) One criterion against surgical treatment

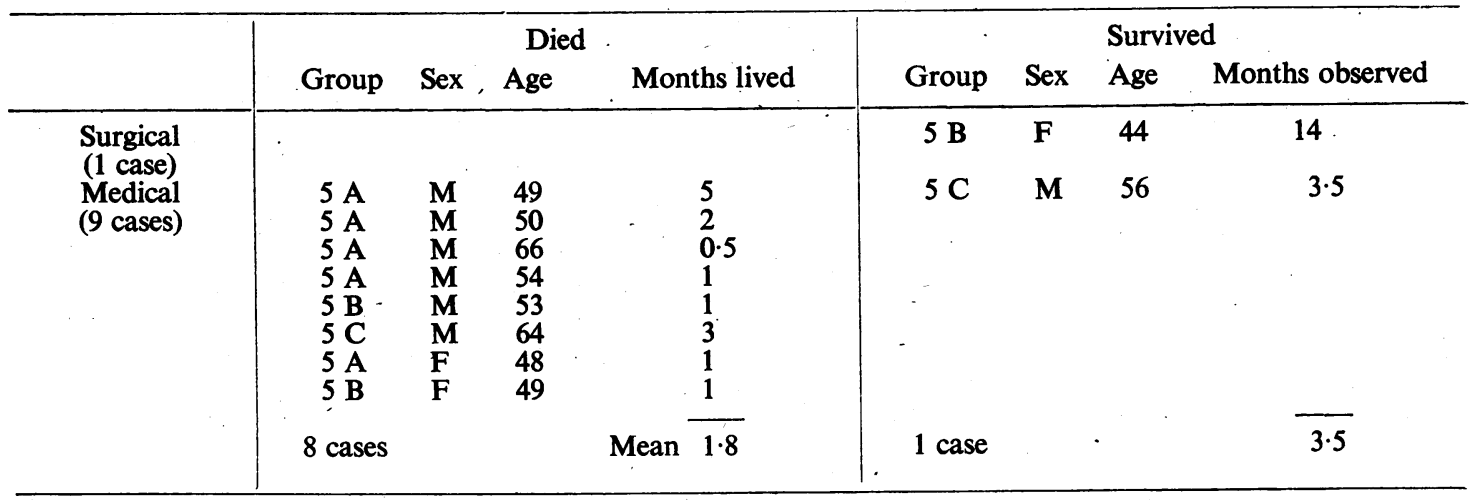

(C) Severe cardiac or renal failure

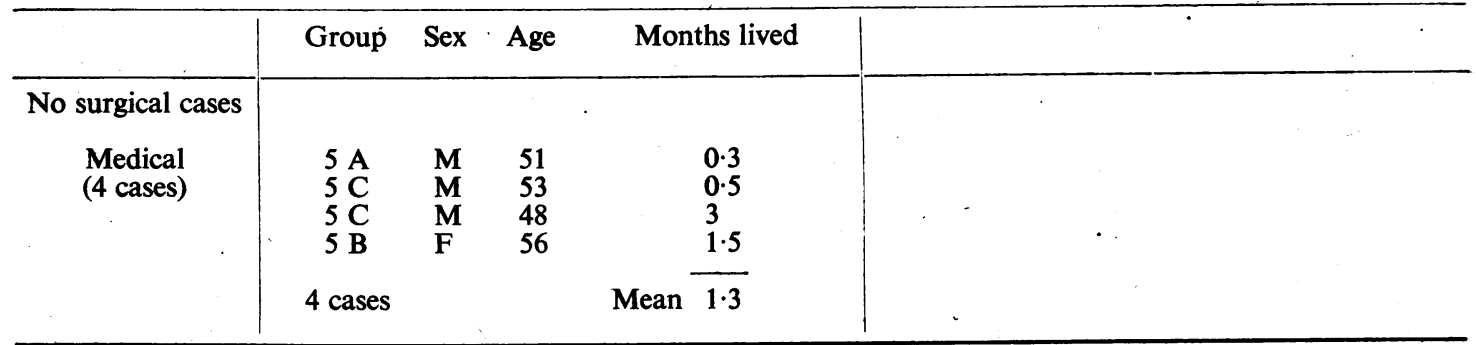

average expectation of life of less than two months, no harm can be done by operation, and possibly some good to the patients, as well as providing an advance in knowledge.

In malignant hypertension surgical treatment seems to lead to greater well-being in surviving patients on a larger scale than would be deduced from the concomitant small remission of objective findings. There are indications, falling short however of statistical significance, that the risk of death may be lowered by operation. Valuable evidence could probably be obtained if operation were performed on alternate cases for which physicians recommend operation and surgeons disagree. 


\section{SUMMARY AND CONCLUSIONS}

One hundred and fifty-one patients, suffering from essential hypertension, form the basis of the present study. They have been carefully investigated and their progress observed over a number of years.

For comparative purposes they have been divided into two groups. The first, numbering 96 patients, received purely medical treatment-rest and sedation. The seeond group, composed of 55 patients, was submitted to sympathectomy.

Largely as a result of changing standards regarding the indications for surgical intervention and with widening experience of the procedure over the past nine years, it has been possible retrospectively to match our surgical group in their pre-operative state with a corresponding series of medical cases in whom for one reason or another surgery was not employed.

By subdividing the medical and surgical cases into smaller categories alike in sex, age, retinal state, cardiac and renal function, and diastolic blood pressure, as determined before the start of therapy, accurate comparison was facilitated and the findings observed a year later in each group reassessed. The results thus obtained have been submitted to statistical analysis. For a variety of reasons 22 medical cases were found unsuitable for comparison and were discarded.

The statistical investigation indicates that in benign hypertension at the end of one year and also at the third anniversary of surgical treatment the sympathectomized patients experience a greater relief of symptoms than corresponding medical groups. Almost all in the surgical group were able to work and many were free from symptoms.
By the end of a year the diastolic blood pressure showed on the average a fall of approximately $8 \mathrm{~mm}$. $\mathrm{Hg}$. in the surgical group, whereas amongst those patients treated exclusively by medical measures it had tended to rise by about an average of $8 \mathrm{~mm}$. after the same length of time. In the surgical group there was also a slight improvement in the retinal grade. In this respect the medical cases showed no change.

The general conclusion is that when our two groups are compared those patients who receive surgical treatment for their benign hypertension are subjectively considerably better than those treated medically. There is less change in the level of the diastolic pressure.

The death rate for persons whose symptoms of so-called benign hypertension lead them to seek help in the hospital is about five times that prevailing in the population as a whole. From our small numbers submitted to analysis there is no evidence of any difference in the mortality rates in the two groups of medically and surgically treated patients.

In malignant hypertension, the data available from a comparatively small number of patients-30 in all-suggest that surgery leads to greater well-being in survivors, but a much larger series is required if statistical proof is to be obtained.

We gladly express our warmest thanks to our surgical colleagues, Prof. Norman Dott, Prof. Sir James Learmonth, and Mr. George Alexander, who by their generous cooperation have made the present investigations possible. Dr. Sven Hammarström of Stockholm has kindly placed some as yet unpublished observations at our disposal.

\section{REFERENCES}

Adson, A. W., Craig, W. M., and Brown, G. E. (1936). Surg. Gyn. and Obst., $62,314$.

- (1934). J. Amer. med. Ass., 102, 115.

Allen, E. V., and Adson, A. W. (1940). Ann. intern. Med., 14, 289.

Bechgaard, P. (1946). Act. med. Scand., 172 (suppl.).

Cameron, J. D. S. (1933-4). Trans. Med.-Chir. Soc. Edin., 93, 73.

Flaxman, N. (1944). Ann. intern. Med., 20, 120.

Grimson, K. S. (1947). Advances in Internal Medicine. New York, Vol. 2, p. 173

Hammarström, S. (1947). Act. med. Scand., 192 (suppl.):

- (1949). Personal communication, to be published.

Hunter, A., and Rogers, O. H. (1923). Trans. Actuarial Soc. Amer., 24, 378.
Peet, M. M., Woods, W. W., and Braden, S. (1940). J. Amer. med. Ass., 115, 1875.

Peters, J. P:, and Van Slyke, D. D. (1946). Quantitative Clinical Chemistry, 2nd ed. London. Vol. 1, p. 840.

Rogers, W. F., and Palmer, R. S. (1946-7). Amer. Pract., 1, 459.

Smithwick, R. H. (1940). Surgery, 7, 1.

(1944). Arch. Surg., 49, 180.

(1948). Brit. med. J., 1, 237.

Ungerleider, H. E., and Gubner, R. (1942). Amer. Heart J., 24, 494.

Wagener, H. P., and Keith, N. M. (1939). Medicine, $18,317$. 